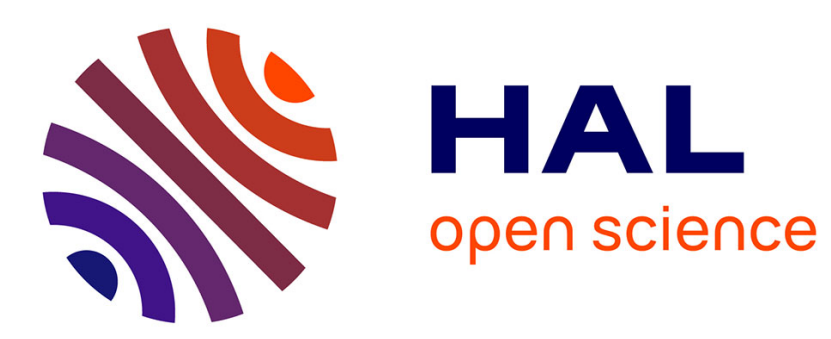

\title{
On the value of operationally synthesized multiple-Doppler wind fields
}

Olivier Bousquet, Pierre Tabary, J. Parent-Du-Chatelet

\section{To cite this version:}

Olivier Bousquet, Pierre Tabary, J. Parent-Du-Chatelet. On the value of operationally synthesized multiple-Doppler wind fields. Geophysical Research Letters, 2007, Geophys. Res. Lett., 34, L22813, doi:10.1029/2007GL030464. 10.1029/2007GL030464 . meteo-00319111

\section{HAL Id: meteo-00319111}

\section{https://hal-meteofrance.archives-ouvertes.fr/meteo-00319111}

Submitted on 29 Oct 2021

HAL is a multi-disciplinary open access archive for the deposit and dissemination of scientific research documents, whether they are published or not. The documents may come from teaching and research institutions in France or abroad, or from public or private research centers.
L'archive ouverte pluridisciplinaire HAL, est destinée au dépôt et à la diffusion de documents scientifiques de niveau recherche, publiés ou non, émanant des établissements d'enseignement et de recherche français ou étrangers, des laboratoires publics ou privés. 


\title{
On the value of operationally synthesized multiple-Doppler wind fields
}

\author{
Olivier Bousquet, ${ }^{1}$ Pierre Tabary, ${ }^{1}$ and Jacques Parent du Châtelet ${ }^{1}$ \\ Received 27 April 2007; revised 11 September 2007; accepted 15 October 2007; published 29 November 2007.
}

[1] The ability to collect radial velocity measurements at long range resulting from the deployment of innovative Doppler schemes within operational radar networks brings new perspectives in terms of exploitation of operational Doppler data, including the ability to routinely retrieve meso- $\beta$ three-dimensional (3-D) multiple-Doppler wind fields over extensive areas. In this paper, we evaluate the potential of this new capability in terms of operational applications using radar data collected by the French radar network ARAMIS. The retrieved 3-D wind fields are shown to provide reliable and continuous mapping of the kinematic structure of rain events and appear particularly suitable for both short term forecasting and model verification purposes. Citation: Bousquet, O., P. Tabary, and J. Parent du Châtelet (2007), On the value of operationally synthesized multipleDoppler wind fields, Geophys. Res. Lett., 34, L22813, doi:10.1029/2007GL030464.

\section{Introduction}

[2] Although three-dimensional (3-D) dual- and multipleDoppler winds inferred from conventional Doppler radar networks have been used for more than 25 years in research mode [e.g., Wakimoto and Srivastava, 2003], current operational applications of Doppler radar measurements remain surprisingly limited to single-Doppler analyses such as Velocity Azimuth Display analysis (VAD) [Browning and Wexler, 1968], or automated short range detection of wind shifts and microburst in the vicinity of major airports [e.g., Wilson et al., 1984]. The main explanation for this lack of advanced operational Doppler use is related to the "Doppler dilemma" ensuing from the inverse relationship between the unambiguous range and the unambiguous velocity [Doviak and Zrnic, 1993], which constrains most national weather services to restrict their Doppler measurements to short range $(\sim 100 \mathrm{~km})$ in order to mitigate velocity ambiguities resulting from the aliasing of radial velocities outside of the Nyquist interval. Because the structure of most operational radar networks is characterized by extensive $(>200 \mathrm{~km})$ radar separation distance, this acts to dramatically restrict the overlapping areas where airflow can be successfully reconstructed, and does not allow for adequate dual- or multiple-Doppler wind synthesis. For this reason reconstruction of 3-D wind fields from operational Doppler radar networks has never been carried out consistently except for short periods of time during which extra research Doppler radars were added in the context of field experiments [e.g., Chong et al., 2000].

\footnotetext{
${ }^{1}$ Météo-France, Trappes, France.
}

Copyright 2007 by the American Geophysical Union. 0094-8276/07/2007GL030464
[3] Thanks to the advent of innovative Doppler schemes such as Multiple-PRT (pulse repetition time) schemes, which have been recently tested in operational radar systems [Torres et al., 2004; Tabary et al., 2006], it has however become possible to defeat this long lasting 'Doppler dilemma' and achieve extensive Doppler coverage while keeping velocity aliasing at a marginal rate. Together with improvements in radar data analysis allowing to eliminate areas of ill-conditioned analysis resulting from geometrical limitations in dual-Doppler configuration [Bousquet and Chong, 1998; Chong and Bousquet, 2001], these achievements open new perspectives in terms of exploitation of the Doppler information including, for the first time, the ability to routinely perform multiple-Doppler analysis within precipitating regions from operational weather radar systems. The benefit of such capability, which has long been a recurring demand of weather forecasters, is to ease the interpretation of raw radar measurements by providing an immediate and synthetic view of the mesoscale wind structure that even a non radar specialist can easily understand.

[4] In this perspective, an experiment has been started in France in November 2006 to produce real time multiple Doppler wind fields in an operational framework. This experiment has been made possible by the operational deployment of a novel 'staggered triple-PRT' Doppler scheme and the subsequent availability of Doppler measurements up to long range $(250 \mathrm{~km})$. The aim of this study is to illustrate the potential of this new product with a particular emphasis on short term forecasting and numerical weather prediction (NWP) model verification applications. The paper is organized as follow: The French radar network, experimental setup and analysis techniques relied upon to produce 3-D wind fields are briefly described in section 2 . Examples of reconstructed wind fields inferred from observations collected during a long lasting frontal precipitation event are shown in section 3 and compared against numerical outputs of the French, new-generation, mesoscale model AROME (Applications of Research to Operations at MesoscalE). Finally, section 4 concludes with a short discussion on the generalization of this development to a nationwide radar network.

\section{Experimental Setup}

\subsection{Radar Network and Experiment Design}

[5] The French operational radar network, named ARAMIS, was built in the early 90's for rain detection purposes and was originally composed of 14 conventional (non Doppler) radars. In 2002, a 6-year duration upgrade program [Parent du Châtelet et al., 2003] was initiated to fill some gaps within the radar coverage and introduce Doppler capabilities. As of today, 8 new Doppler radars have been installed, a numerical receiver has been devel- 

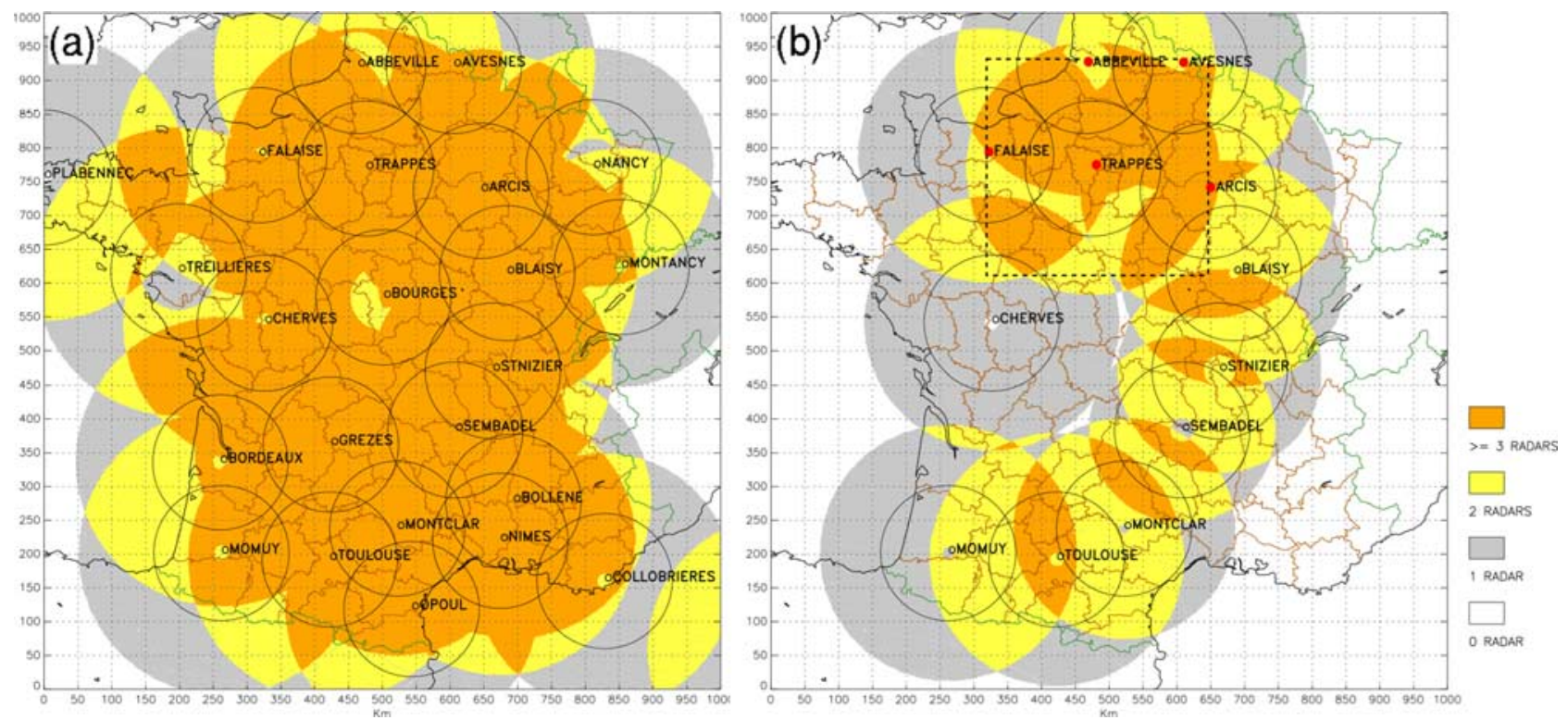

Figure 1. Map of the ARAMIS network superimposed on Doppler radar overlapping (color coded) at $2 \mathrm{~km}$ MSL: (a) anticipated Doppler radars and overlapping in 2008 and (b) actual Doppler radars and overlapping as of January 2007. The $100 \mathrm{~km}$ ranges of measurement associated with each radar are indicated by black circles. In Figure $1 \mathrm{~b}$ the red dots show the location of the 5 radars used to reconstruct the 3-D airflow within the $320 \times 320 \times 12 \mathrm{~km}^{3}$ experimental domain (square).

oped to Dopplerize the original radars and the "staggered triple PRT" Doppler scheme proposed by Tabary et al. [2006] was operationally deployed within the entire radar network to address the mitigation of range and velocity ambiguities [Zrnic and Mahapatra, 1985]. With that scheme, Doppler velocities are available simultaneously with reflectivity up to $250 \mathrm{~km}$ and with no ambiguity (the Nyquist velocity is equal to $60 \mathrm{~m} \mathrm{~s}^{-1}$ ). The average dealiasing success rate achieved from the triple-PRT scheme is 90\% (the reader is referred to Tabary et al. [2006] for a thorough assessment of the quality of the radial velocities in various weather conditions).

[6] By late 2007, ARAMIS will comprise 24 Doppler radars (Figure 1a) covering most of the French territory, with radar baselines ranging from $\sim 200 \mathrm{~km}$ in the northern part of the country down to less than $70 \mathrm{~km}$ in the southern part. The ability of Doppler measurements up to $250 \mathrm{~km}$ will then allow multiple-Doppler wind retrievals over $\sim 50 \%$ of the French territory at low $(\leq 1 \mathrm{~km}$ MSL $)$ and high ( $>10 \mathrm{~km} \mathrm{MSL}$ ) levels, up to $\sim 90 \%$ between $2 \mathrm{~km}$ and $7 \mathrm{~km}$ MSL (Figure 1a). As of today, the Dopplerization of the network is about half completed, which already allows for significant Doppler radar overlapping, especially in the northern part of the country (Figure 1b), where the test area for the experimental 3-D product has been set. This experimental domain measures $320 \times 320 \times 12 \mathrm{~km}^{3}$ and is centered on Trappes C-band polarimetric Doppler radar that is located $\sim 30 \mathrm{~km}$ to the southwest of Paris. It is also covered by 4 additional C-band operational Doppler radars respectively located at Arcis, Falaise, Abbeville, and Avesnes (Figure 1b). All radars perform a complete volume scan in 15 minutes according to the volume coverage pattern (VCP) demonstrated in Table 1. The scanning strategies are radar specific and consist in three $5^{\prime}$ cycles that are repeated every $15^{\prime}$. Except for Trappes and Arcis radars all other radars are characterized by limited scan modes that consist in 2 to 3 distinct elevation angles repeated every $5^{\prime}$ (Table 1 ). The vertical and horizontal resolutions of the domain are set to $500 \mathrm{~m}$ and $2.5 \mathrm{~km}$ to be consistent with unavoidable smoothing inherent to radar beam widths of $\sim 1^{\circ}$. Due to the principle of ground-based radar measurements, the multiple-Doppler radar sampling within this domain is heterogeneous, which influences the quality of the retrieved wind fields (the more independent measurements at a given point, the better the quality of the retrieved wind field). The multiple-Doppler radar coverage is thus somewhat restricted in the lowest $(\leq 1 \mathrm{~km} \mathrm{MSL})$ and highest $(>10 \mathrm{~km}$ MSL) layers due to lengthy radar separation distances and limited scanning strategies, but is much more significant between $2.5 \mathrm{~km}$ and $7 \mathrm{~km}$ MSL, where multiple-Doppler measurements (3 or more independent radar observations) are available within $\sim 100 \%$ of the domain (see Figure $\mathrm{S}^{1}{ }^{1}$ ).

\subsection{Data and Analysis Issues}

[7] Observations from the 5 radars are centralized and processed in a fully automated way every $15^{\prime}$. Data consist in operational Plan Position Indicators (PPI) of Doppler velocity and reflectivity projected on a $1 \mathrm{~km}^{2}$ Cartesian grid. The data pre-processing includes the removal of non meteorological echoes (e.g. ground clutter) and the application of a $5 \times 5 \mathrm{~km}^{2}$ median filter on Doppler velocity to filter out potential dealiasing failures [Tabary et al., 2006]. In order to account for the non-simultaneity of the measurements, data are synchronized with respect to the ending time of the current $15^{\prime}$ cycle using a $32-\mathrm{km}$ resolution advection vector

\footnotetext{
${ }^{1}$ Auxiliary materials are available in the HTML. doi:10.1029/ 2007GL030464.
} 
Table 1. Elevation Angles Corresponding to the Scanning Strategy of the 5 Doppler Radars Covering the Greater Paris Area ${ }^{\mathrm{a}}$

\begin{tabular}{lccccccccccccccccccc}
\hline & \multicolumn{10}{c}{} & \multicolumn{11}{c}{ Tilt } \\
\cline { 2 - 3 } & 1 & 2 & 3 & 4 & 5 & 6 & 7 & 8 & 9 & 10 & 11 & 12 & 13 & 14 & 15 & 16 & 17 & 18 \\
\hline Trappes & 90 & $\mathbf{7 . 5}$ & 0.8 & 1.5 & $\mathbf{4 . 5}$ & 0.4 & $\mathbf{9 . 5}$ & $\mathbf{6 . 5}$ & 0.8 & 1.5 & $\mathbf{3 . 6}$ & 0.4 & $\mathbf{8 . 5}$ & $\mathbf{5 . 5}$ & $\mathbf{0 . 8}$ & $\mathbf{1 . 5}$ & $\mathbf{2 . 5}$ & $\mathbf{0 . 4}$ \\
Arcis & $\mathbf{4 . 0}$ & 1.1 & 0.4 & - & - & - & $\mathbf{3 . 0}$ & 1.1 & 0.4 & - & - & - & $\mathbf{2 . 0}$ & $\mathbf{1 . 1}$ & $\mathbf{0 . 4}$ & - & - & - \\
Falaise & 1.6 & 1.1 & 0.4 & - & - & - & 1.6 & 1.1 & 0.4 & - & - & - & $\mathbf{1 . 6}$ & $\mathbf{1 . 1}$ & $\mathbf{0 . 4}$ & - & - & - \\
Abbeville & 0.4 & 1.1 & 0.4 & - & - & - & 0.4 & 1.1 & 0.4 & - & - & - & 0.4 & $\mathbf{1 . 1}$ & $\mathbf{0 . 4}$ & - & - & - \\
Avesnes & 1.6 & 1.0 & 0.4 & - & - & - & 1.6 & 1.0 & 0.4 & - & - & - & $\mathbf{1 . 6}$ & $\mathbf{1 . 0}$ & $\mathbf{0 . 4}$ & - & - & - \\
\hline
\end{tabular}

${ }^{\mathrm{a}} \mathrm{A}$ super cycle (18 tilts) is composed of three 5' cycles (6 tilts). Bold values indicate tilts that are used to retrieve the 3-D airflow. Elevation angles are in degrees.

field obtained by cross-correlating successive $5^{\prime}$ pseudoCAPPI reflectivity images. It is radar specific and is computed every $5^{\prime}$. Radar elevation angles considered in this analysis are shown in Table 1.

[8] Once pre-processed, data are interpolated into the Cartesian grid and ingested in the multiple-Doppler synthesis and continuity adjustment technique (MUSCAT) initially proposed by Bousquet and Chong [1998]. MUSCAT embodies a fully variational approach that permits a simultaneous and computationally-efficient solution of the three Cartesian wind components even along the baseline connecting a pair of ground-based radars where ill-conditioned analysis traditionally occurs [Chong and Bousquet, 2001]. Because the three-dimensional wind field reconstructed by MUSCAT represents a least squares fit to the available observations and does not perfectly satisfy the mass continuity equation, an a posteriori upward integration is performed following O'Brien [1970]. Overall, decoding, interpolating and resolving the $3-\mathrm{D}$ wind field on a domain of 375,000 grid points $\left(320 \times 320 \times 12 \mathrm{~km}^{3}\right)$ requires between 90 and 120 seconds of computation time on a $1.8 \mathrm{GHz}$ dual-processor LINUX server.

\section{Examples of Reconstructed Wind Fields and Potential Applications}

\subsection{Observation of a Long Lasting Frontal Precipitation Event}

[9] The operational potential of this product is evaluated through analysis of observations collected during a long lasting frontal precipitation event that crossed the French territory on 13-14 February 2007. This system, which produced continuous rainfall over Northern France for about 24 hours, has been consistently sampled by the 5 radars covering the greater Paris area. Reflectivity and wind direction at $2 \mathrm{~km}$ MSL, as inferred from the analysis of radar observations collected at 06:00, 12:00, 14:00, and 16:00 UTC on 14 February, are shown in Figure 2. During the first 12 hours of observation the situation remained stable and was characterized by weak to moderate precipitation and uniform SW'ly flow over the experimental area (Figure 2a and Animation S1). Around 12:00 UTC (Figure 2b), a distinct flow regime began to emerge in the northwestern part of the domain as winds rapidly turned to NW'ly. This sudden change corresponds to the arrival of a cold front within the domain. The kinematical boundaries of the front, which can be unambiguously identified from a wind shift-based criterion, seem in good agreement with those derived from surface observations at this time. The wind transition at the front was rather sharp, with weak
NW'ly winds $\left(\sim 5-10 \mathrm{~m} \cdot \mathrm{s}^{-1}\right)$ before and stronger southwesterly flow (20-25 m.s ${ }^{-1}$ ) after (Figure $\left.3 b\right)$. The occurrence of large scale subsidence is suggested by the systematic observation of strong reflectivity values ahead of the wind shift. Notice that, at this height, the domain is fully covered by at least 2 radars such that echo free regions in the reflectivity field denote the absence of rain. By 14:00 UTC (Figure 2c), the front has progressed eastward, resulting in the expansion of NW'ly winds over half of the experimental area. NW'ly flow then gradually expanded into the rest of the domain (Figure 2d). Although detailed observations of the kinematic structure and evolution of fronts by the means of research radars have already been performed in the context of field experiments [Roux et al., 1993; Stonitsch and Markowski, 2007], this is, to the best of our knowledge, the first time that similar observations are performed in a fully operational framework.

[10] Even though these retrieved wind fields seem qualitatively reliable, it is important to evaluate these products from a more quantitative perspective. Such task, however, is not trivial as there are currently no other observation means that can provide wind measurements at the space-time resolution achieved by Doppler radars. Figure S2 presents an illustration of ongoing efforts to assess quantitatively the final 3-D product. It shows a comparison between the retrieved 3-D wind field and data from an operational wind profiler located at La Ferté-Vidame (Figure 2a) during this event. Overall there is a good agreement between the two datasets although one can note significant differences between 12 UTC and 15 UTC. Observed differences during this time period, which approximately corresponds to the passage of the front above the profiler site, are due to differences in the temporal resolution of the two datasets (wind profiler data are averaged over a 1-h period). When significant and sudden changes occur in the wind structure the lower temporal resolution of the wind profiler does not allow for an objective comparison against the multipleDoppler winds. If we exclude data collected during this period, the mean difference between the two datasets average around $1 \mathrm{~m} \cdot \mathrm{s}^{-1}$ (wind speed) and $5^{\circ}$ (wind direction) with a RMS error of $2 \mathrm{~m} \cdot \mathrm{s}^{-1}$ and $7^{\circ}$, respectively. Such comparisons have also been carried out on several other situations (not shown here due to lack of space). Overall, the error figures obtained for the 14 February 2007 are quite representative of the typical 3-D wind fields-wind profiler differences.

\subsection{Potential Applications}

[11] The unique information on the kinematic structure of precipitating systems that can be inferred from the opera- 


\section{Reflectivity (dBZ) and wind direction at $2000 \mathrm{~m} \mathrm{MSL}$}

(a) 0600 UTC

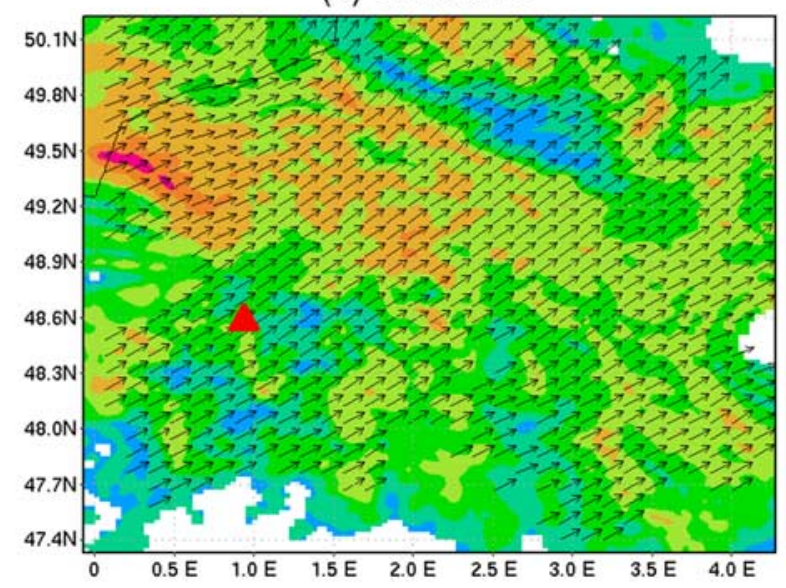

(c) 1400 UTC

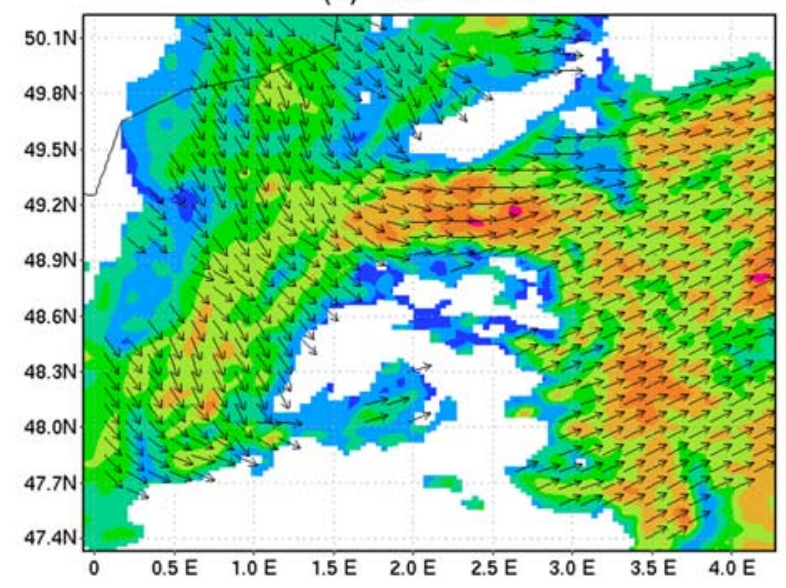

(b) 1200 UTC

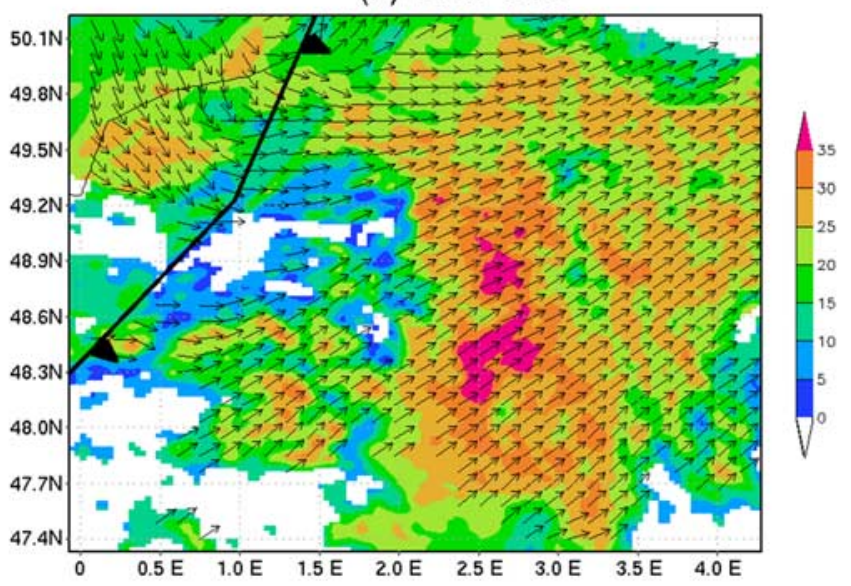

(d) 1600 UTC

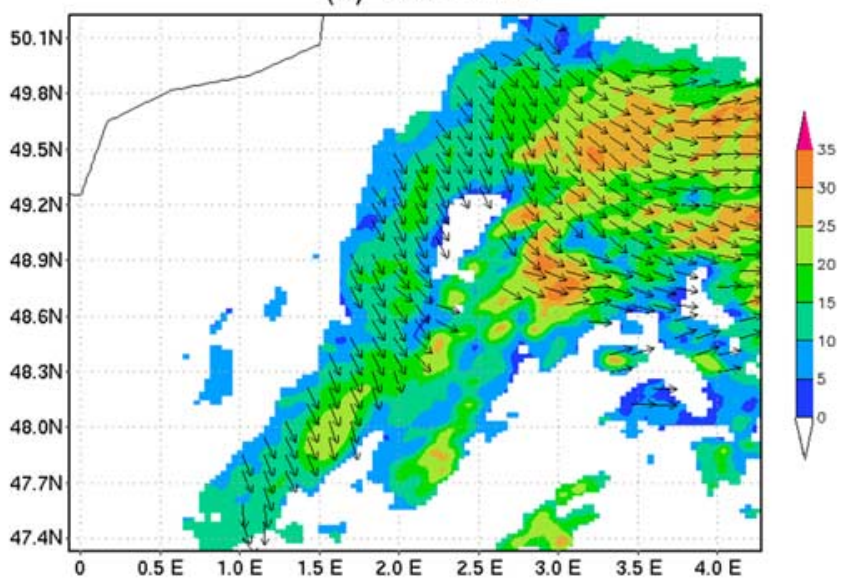

Figure 2. Wind direction (vectors) superimposed on radar reflectivity (dBZ, color coded) at $2.0 \mathrm{~km}$ MSL within the experimental domain shown in Figure 1b, as derived from multiple-Doppler analysis of radar data at (a) 06:00 UTC, (b) 12:00 UTC, (c) 14:00 UTC, and (d) 16:00 UTC on 14 February 2007. One every fourth vector is plotted. The location of the cold front as derived from an operational surface analysis at 12:00 UTC is indicated in Figure 2b. In Figure 2a the red triangle indicates the location of the wind profiler at La Ferté Vidame.

tional retrieval of 3-D multiple-Doppler winds is potentially valuable for many applications. Researchwise, such information could be archived to build a weather database that would be used for statistical analysis purposes, or more traditional case studies. From an operational standpoint, these wind fields could also be used for model validation, model time lag delay correction or to assist weather nowcast. Figure 2 and Animation S1 evidently demonstrate the value of these reconstructed winds in order to identify and monitor key airflow features, such as significant convergence/divergence area or, as in the present case, wind shifts associated with the presence of fronts. As of today, predicting the position of fronts associated with midlatitude baroclinic waves is usually accomplished through combining low resolution operational surface analyses extrapolated a few hours ahead and numerical model forecast outputs. In this respect, the added value resulting from the broad picture afforded by the multiple-Doppler winds is potentially considerable, as it would undoubtedly lead to more accurate forecasts of kinematical frontal boundaries at different height levels.

[12] The recent advent of new, high resolution, limited area NWP systems, such as AROME, HIRLAM, or WRF models that require lots of mesoscale data for validation represents yet another potential operational application for this product. Indeed, unlike traditional wind verification datasets, such as operational analyses or synoptic scale spacing network data in which non linear features have been smoothed away, radar-derived velocity data still contain detailed information on the mesoscale structure of the airflow. For this reason, radar operators that mimic the behavior of real radar systems have been recently proposed to perform direct model validation from radial wind data [e.g., Caumont et al., 2006]. As the native resolution of radial winds is still much higher than that of these models, it is however necessary to re-scale the radar data (to mitigate representativeness errors) through spatially averaging observations from different azimuth directions prior to compar- 
Wind Speed $(\mathrm{m} / \mathrm{s})$ and Direction at $1500 \mathrm{~m} \mathrm{MSL}$

(a) RADAR 0600 UTC

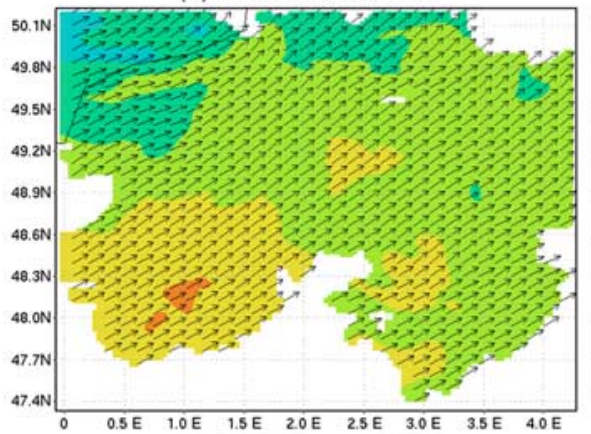

(b) RADAR 1200 UTC

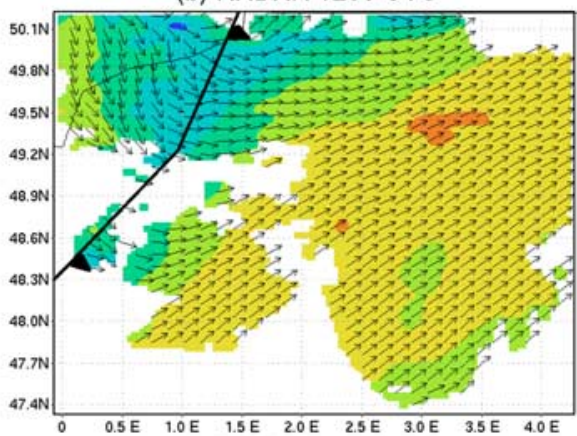

(c) RADAR 1400 UTC

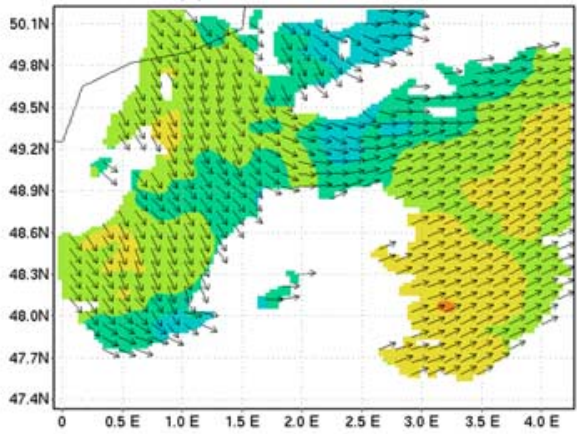

(d) RADAR 1600 UTC

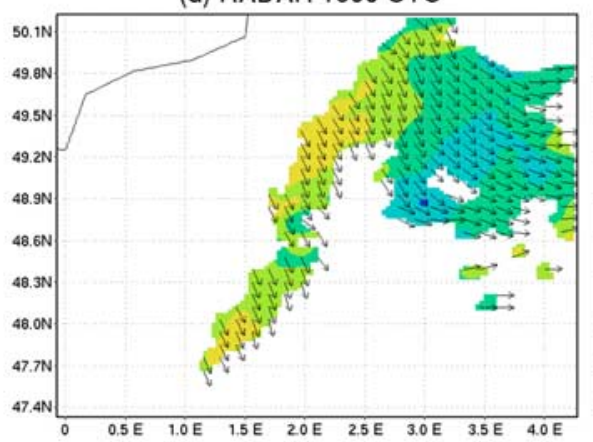

(e) AROME 0600 UTC

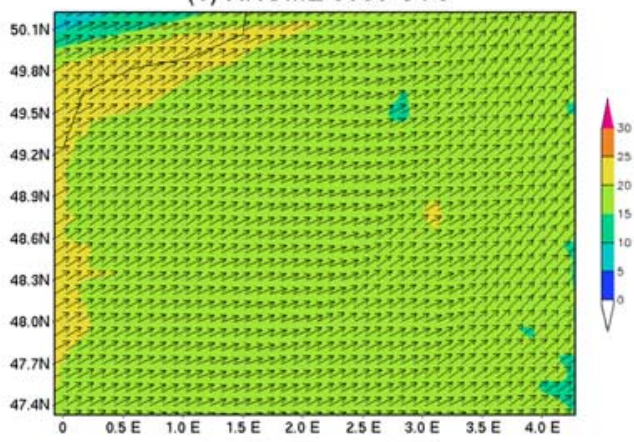

(f) AROME 1200 UTC

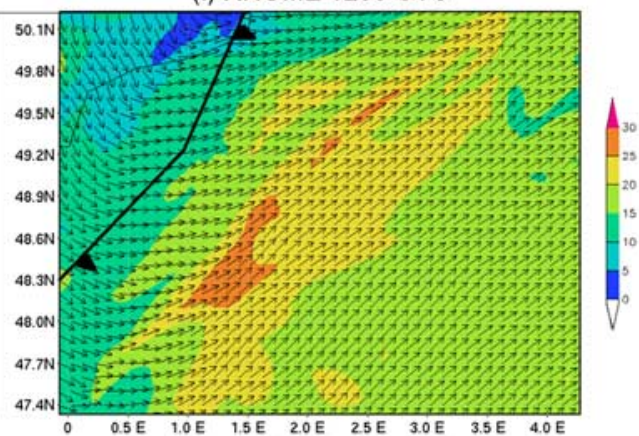

(g) AROME 1400 UTC

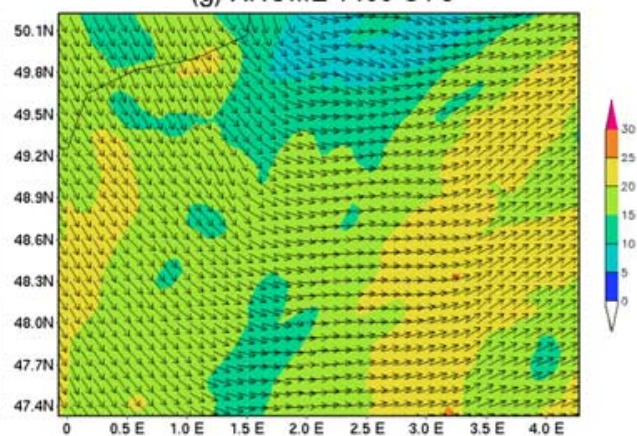

(h) AROME 1600 UTC

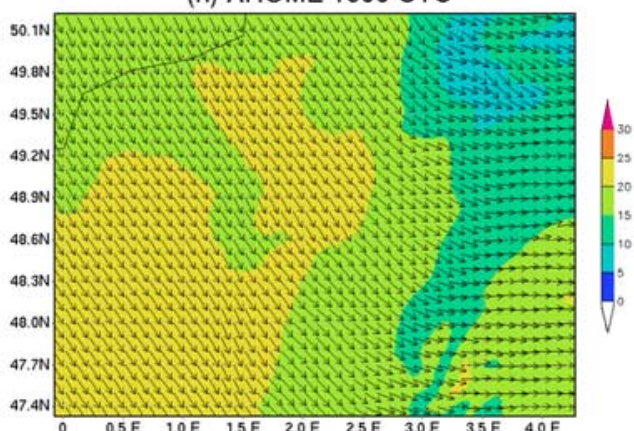

Figure 3. Side by side comparison of (left) radar-derived and (right) AROME wind speed (m.s ${ }^{-1}$, color coded) and direction (vectors) at $1500 \mathrm{~m} \mathrm{MSL}$ at (a) and (e) 06:00 UTC, (b) and (f) 12:00 UTC, (c) and (g) 14:00 UTC, and (d) and (h) 16:00 UTC on 14 February 2007, within the experimental domain shown in Figure 1b. One every fourth vector is plotted. The location of the cold front as derived from an operational surface analysis at 12:00 UTC is indicated in Figures $3 \mathrm{~b}$ and $3 \mathrm{f}$.

ison. A problem with this upscaling process, however, is that it can ultimately cancel biases in wind speed and direction even in the presence of systematic differences between observed and modeled winds [Salonen et al.,
2007]. Because, u, v and w are model state variables, using complete wind fields instead of radial winds may thus allow bypassing radar simulators to perform direct, unbiased model verification. 
[13] To illustrate this capability, Figure 3 presents a side by side comparison of radar- vs. model-derived winds at $1.5 \mathrm{~km}$ MSL valid at 06:00, 12:00, 14:00, and 16:00 UTC, on 14 February 2007. The model winds presented in this study are derived from a 24-hour forecast (60 s time-step) starting at 00 UTC of a prototype version of Météo France's next generation NWP system AROME, whose operational introduction is anticipated in 2008 over mainland France. This version, which runs once a day on a $600 \times 600 \mathrm{~km}^{2}$ domain centered on Paris city, features a $2.5 \mathrm{~km}$ horizontal grid mesh size and 41 vertical levels. Overall, the similarity between the radar and model winds shown in Figure 3 indicates that the level of detail achieved in the retrieved winds is evidently compatible with that required for high resolution NWP model verification, despite the large radar separation distances in the greater Paris area. From a qualitative standpoint, the model performs remarkably well, although one can note a slight misplacement of the kinematical front with respect to both radar-derived and operational surface observations (Figures $3 b-3 f$ ). Because knowledge of these model mistakes is key to better understanding and improving their behavior, information afforded from operationally reconstructed winds may thus represent a valuable tool for model wind verification.

\section{Conclusions and Future Developments}

[14] Thanks to the recent deployment of a new triplePRT scheme within the French radar network, it has become possible to defeat the long lasting 'Doppler dilemma' and to achieve extensive Doppler coverage while keeping Doppler velocity aliasing at a marginal rate. The availability of Doppler measurements up to long range brings new perspectives in terms of exploitation of operational Doppler measurement, including the ability to routinely retrieve 3-D airflow in cloud systems in a fully operational framework. In this context, an experiment has been set up to derive real-time multiple-Doppler winds over Northern France in a totally automated way. The potential of these operationally-synthesized wind fields has been evaluated in terms of operational and research applications using data collected during a long lasting frontal precipitation event observed on 13-14 February 2007. We showed that information inferred from these wind fields can definitely be relied upon to achieve consistent mapping of the dynamic structure of rain events at multiple scales, as well as to easily spot key flow features, such as convergence or wind shift, whose detection present a strong interest for short term forecasting and model verification.

[15] Even though radial velocities, which are the main ingredients of the 3-D wind fields, have already been quantitatively assessed [Tabary et al., 2006], there is still some work ahead to validate quantitatively the 3-D operational multiple-Doppler wind fields. Radiosonde, wind profiler, AMDAR (aircraft meteorological data relay) data and numerical simulations will be used for that purpose. In particular, it is essential to test this approach on different meteorological situations, such as convective events and rapidly evolving systems, as well as to better estimate expected errors in reconstructed wind fields based on uncertainties in raw measurements and associated geometric principles inherent to the wind synthesis technique. The qualitative results obtained on numerous 2007 events have, however, already been considered valuable enough to justify the operational implementation, by 2009 , of an operational nationwide $3-\mathrm{D}$ wind and reflectivity mosaic at Météo France.

[16] Overall, the wind synthesis procedure is very flexible and the addition of new radars in the processing chain is a simple and fast process that requires very little modifications. As newly Dopplerized radars are becoming regularly available in the course of the ongoing upgrade program, we thus look forward to progressively enlarging the domain of restitution to achieve a nationwide coverage by mid 2008. Since the characteristics of ARAMIS are generally either comparable (baselines, radar density) or less sophisticated (scanning strategies) than those of many operational radar networks operated around the world, this development should easily be transposable elsewhere, provided that Doppler velocities are available up to long range $(250 \mathrm{~km})$. This is now operationally possible with the deployment of innovative Doppler schemes such as multiple-PRT. For this reason, we believe that these findings have the potential to change the way operational Doppler radar measurements are used for both operational and research purposes.

\section{References}

Bousquet, O., and M. Chong (1998), A multiple-Doppler synthesis and continuity adjustment technique (MUSCAT) to recover wind components from Doppler radar measurements, J. Atmos. Oceanic Technol., 15, 343359.

Browning, K. A., and R. Wexler (1968), The determination of kinematic properties of a wind field using Doppler radar, J. Appl. Meteorol., 7, $105-113$.

Caumont, O., et al. (2006), A radar simulator for high-resolution nonhydrostatic models, J. Atmos. Oceanic Technol., 23, 1049-1067.

Chong, M., and O. Bousquet (2001), On the application of MUSCAT to a ground-based dual-Doppler radar system, Meteorol. Atmos. Phys., 78, $133-139$.

Chong, M., et al. (2000), Real-time wind synthesis from Doppler radar observations during the Mesoscale Alpine Programme, Bull. Am. Meteorol. Soc., 81, 2953-2962.

Doviak, R. J., and D. S. Zrnic (1993), Doppler Radar and Weather Observations, 2nd ed., Academic, San Diego, Calif.

O'Brien, J. J. (1970), Alternative solutions to the classical vertical velocity problem, J. Appl. Meteorol., 9, 197-203.

Parent du Châtelet, J., M. Guimera, and P. Tabary (2003), The PANTHERE Project of Meteo-France: Extension and upgrade of the French radar network, paper presented at 31st International Conference on Radar Meteorology, Am. Meteorol. Soc., Seattle, Wash.

Roux, F., V. Marecal, and D. Hauser (1993), The 12/13 January 1988 narrow cold-frontal rainband observed during MFDP/FRONTS 87. Part I: Kinematics and thermodynamics, J. Atmos. Sci., 50, 951-974.

Salonen, K., et al. (2007), Bias estimation of Doppler radar radial winds, paper presented at 33rd Conference on Radar Meteorology, Am. Meteorol. Soc., Cairns, Queensl., Australia. (Available at http://ams.confex.com/ ams/pdfpapers/123179.pdf.)

Stonitsch, J. R., and P. M. Markowski (2007), Unusually long duration, multiple-Doppler Radar observations of a front in a convective boundary layer, Mon. Weather Rev., 135, 93-117.

Tabary, P., F. Guibert, L. Perier, and J. Parent du Châtelet (2006), An operational triple-PRT scheme for the French radar network, J. Atmos. Oceanic Technol., 23, 1645-1656.

Torres, S. M., Y. F. Dubel, and D. S. Zrnić (2004), Design, implementation, and demonstration of a staggered PRT algorithm for the WSR-88D, J. Atmos. Oceanic Technol., 21, 1389-1399.

Wakimoto, M. R., and R. Srivastava (Eds.) (2003), Radar and Atmospheric Science: A Collection of Essays in Honor of David Atlas, Meteorol. Monogr., 30. 
Wilson, J. W., R. D. Roberts, C. Kessinger, and J. McCarthy (1984), Microburst wind structure and evaluation of Doppler radar for airport wind shear detection, J. Appl. Meteorol., 23, 898-915.
Zrnic, D. S., and P. Mahapatra (1985), Two methods of ambiguity resolution in pulsed Doppler weather radars, IEEE Trans. Aerosp. Electron. Syst., 21, 470-483.

O. Bousquet, J. Parent du Châtelet, and P. Tabary, Météo-France, 7, Rue Teisserenc-de-Bort, F-78195 Trappes, France. (olivier.bousquet@meteo.fr) 